\title{
How Health Education Teachers Start Their Lesson: A Qualitative Inquiry at Education Campuses of Nepal
}

\author{
Kusum Raj Subedi ${ }^{*}$, Bhagwan Aryal'2, Suprabha Subedi ${ }^{3}$ \\ ${ }^{1}$ Shaheed Smriti Multiple Campus, Chitwan, Nepal \\ ${ }^{2}$ University Campus, Tribhuvan University, Kathmandu, Nepal \\ ${ }^{3}$ Tribhuvan University, Kathmandu, Nepal \\ Email: ^kusumrajsubedi@gmail.com
}

How to cite this paper: Subedi, K. R., Aryal, B., \& Subedi, S. (2021). How Health Education Teachers Start Their Lesson: A Qualitative Inquiry at Education Campuses of Nepal. Creative Education, 12, 573-583. https://doi.org/10.4236/ce.2021.123039

Received: January 30, 2021

Accepted: March 14, 2021

Published: March 17, 2021

Copyright $\odot 2021$ by author(s) and Scientific Research Publishing Inc. This work is licensed under the Creative Commons Attribution International License (CC BY 4.0).

http://creativecommons.org/licenses/by/4.0/ (c) (i) Open Access

\begin{abstract}
Introduction: Set induction is an important initial act used by the teachers to start effective classroom teaching learning. It is an integral part of general education and has been considered as producing beneficial outcomes to both teachers and students. However, in recent years, the quality of teachers training program has been questioned and there is limited evidence on if teachers are aware of set induction skills and their use in their classroom teaching. In this study, we assessed the level of knowledge in relations to skills of set induction and its' use in real classroom teaching among the health education teachers in Education Campuses. Methods. Qualitative phenomenological research design was used to collect data from the health education teachers, involved in teaching health education for Undergraduate or Master level programs in four purposively selected districts (Dolakha, Kathmandu, Bhaktapur and Chitwan). Altogether 18 health education teachers participated in-depth qualitative interviews, 19 teachers' were observed in their classroom teaching, and four Focus Group Discussions (26 teachers). The qualitative data were analyzed thematically. Findings. Findings show that most of the teachers showed some level of knowledge on pedagogical teaching that they had been using at the starting of the lessons. However, they perceived the existing knowledge inadequate. Teachers noted use of a range of strategies is essential to effective induction, such as review of previous topic, summarizing previously taught lesson, asking questions, encouraging interaction, storytelling etc. Further, the teachers emphasized the use of these sets of induction skills essential to ensure quality health education teaching learning. However, they acknowledged that there has been a big gap in using these sets of induction skills to the classroom lesson preparation and teaching. The teachers noted
\end{abstract}


few reasons for such gaps, including lack of adequate teaching learning materials, insufficient time, high workload, and inadequate number of qualified health education teachers etc. Conclusion: While addressing the challenges and gaps the health education teachers have noted, there is a need for improving sets of induction skills among the health education teachers and emphasizing effective use of these skills for classroom teaching learning.

\section{Keywords}

Set Induction, Health Education, Health Education Teacher, Teaching, Pedagogy

\section{Introduction}

Set inductions in a lesson, also referred to as interest approaches, are a variety of different techniques used at the beginning of a lesson in effort to peak interest or switch the learners mind to a different thought process (Oman, 2002). It is an important initial act used by the teachers to start effective classroom teaching learning. The introduction to lesson must be interesting so as to absorb the students in what follows. In spite of individual differences among students in regard to intelligence, knowledge, personality, maturity level, etc. the teacher should plan the lesson in order to brow and sustain their interest. Although it is an important part of every classroom activity and a core pedagogical skill to be learnt through teachers training program, its quality in Nepalese teachers training program in recent years has been questioned and there is limited evidence on if teachers are aware of set induction skills and their use in their classroom teaching.

Teaching is a set of skills for the realization of a specified set of objectives (Aggarwal, 2014). The changing role of the teacher in education has been the result of plurality of intertwining influences, philosophical, psychological, social, technological and educational (Popkewitz, 2012). The shift in emphasis from the teacher to the pupil as the central figure in the process of education has introduced effective techniques in teaching. The merge of instructional activities with the realization of specific and clear cut learning outcomes has inevitably led to a reassessment of the teacher's role in the classroom. Set induction is one of the important skills of teachers to prepare students ready towards study. Before the teachers make the students ready to learn, they could not lead the lesson. Thus, the knowledge of skill of set induction, and its application techniques are necessary to every teacher for this purpose.

The components of set induction skill are (Allen \& Ryan, 1968):

1) Using previous knowledge;

2) Using appropriate devices.

Introduction serves as a bridge between new knowledge of a new topic and previously learnt knowledge. Appropriate devices used for an introduction are 
narrations, illustration (charts, film strips, slides) questions, similarities and analogies. Care should be taken to see that there is a direct link between the new topic and previous knowledge. Relevant and logical statements are to be made. This part of the lesson would not take more than 5 - 7 minutes and the teacher adopts to use this skill.

These set inductions, sometimes referred to as an interest approach or anticipatory sets, can be defined as an event to focus and grab the students attention and normally takes place, but does not have to be, toward the beginning of the class period; can be put into place when introducing a new or unfamiliar topic (Oman, 2001). It is thought that to enable learners to reach higher intellectual standards, we will have to improve our ability to provoke thought, curiosity, and drive (Wiggins \& McTighe, 2005).

Schuck (1970) responds to the topic of set inductions by claiming the readings and studies claim set as a crucial variable in determining classroom learning styles and that teachers are the primary agent in bringing forth curiosity in a student and introducing a student's set in the direction of learning.

According to Dyer and Osborne (1999), "the teaching approach used by educators is very important to the success of the learning process". A study by Schunk (2012) revealed that in determining student retention and achievement, set induction is a vital variable to investigate. He explains the main point of a set induction by stating the following:

The purpose of the set induction procedure is to focus pupil attention on some commonly known experimental referent (orientation) that becomes the vehicle by which the teacher makes the passage from the known to new material (transition) and builds continuity from lesson to lesson. The induced set lends meaning to new material through the use of analogy rather than by simple association (operation) and encourages pupil involvement in the lesson as judged by the teacher (evaluation) (p. 406).

In relation to social interaction, the induction of an appropriate set can be defined as the initial strategy employed to establish a frame of reference, deliberately designed to facilitate the development of a communication link between the expectations of the participants and the realities of the situation (Hargie, 2016).

In the context of teaching, set induction is therefore used at the beginning of a class so as to prepare students for optimum content assimilation. Set Induction has 5 main purposes: to gain attention, to arouse motivation, to assess understanding of prior learning, to provide an overview of content that will follow, and to determine the expectations of participants. There are 4 key components of set induction: perceptual, cognitive, motivational and social.

The major goal of any teacher education program is to provide teachers with essential knowledge and skills required for effective teaching. The health education curriculum at Tribhuvan University (TU) aims to produce quality teacher and teacher educator in the field of health education. The courses include both 
content and pedagogical skills. Such skills are practiced in the micro-teaching programs too. However, the health education teachers after the end of their degree find it hard to implement the knowledge and skills received from the courses.

Education degree holders are called the trained one in Nepal. Nevertheless, they themselves are not able to practice or they do not practice trained skills in their respective institutions. Karmacharya (2006) says that despite the emphasis on teacher training, and regardless of the growing literature on teacher preparation and training research, this area has remained a subject of criticism for failing to prepare quality teachers adequately in Nepal.

Health education is a behavioral science to promote health awareness. It also includes sensitive and delicate contents. It is imperative that health education teachers be thoroughly acquainted with the knowledge and skill of opening a class in an effective way. The manner in which teachers transmit information and go about the lesson is an important area of inquiry which could lead to the improvement of education (Eisner, 2017). Although TU health education courses focus on linking knowledge and skills for teaching by using various psychological and educational approaches of starting a class, the real classroom practice is still perceived less effective.

\section{Objective of the Study}

The study aimed to identify the knowledge of set induction skill and its application by health education teachers in classroom in the teachers training program of Tribhuvan University (TU).

\section{Research Methods and Processes}

This study used a qualitative phenomenology method. It incorporated all the health education teachers teaching at bachelor and master levels at different campuses affiliated to TU in Bagamati Province of Nepal. Sample campuses and teachers from 4 districts of 3 geographical regions (Mountain-Dolakha, HillKathmandu and Bhaktapur, and Terai-Chitwan) were selected purposively and inclusive of geographic balance. Eighteen teachers were interviewed in-depth and 19 teachers' classroom instructions were observed, whereas 4 Focus Group Discussions (FGDs) were conducted. Twenty six teachers participated in the FGDs. However, the teachers who were teaching in two or more campuses were included only once as sample in the study.

An in-depth interview guideline was used to collect data related to teachers' knowledge on using skill of set induction. It included the guiding questions on skill of set induction and its activities as well as how teachers start their class using the previous knowledge and appropriate devices. As for the class observation, an observation guideline of use of set induction skills was used. It explored the competency of the trained teachers if they demonstrated the skill in classroom while opening up a lesson. An FGD topic guide was also used to dig dee- 
per into the situation and perceived causes of not using the skill of set induction.

Trustworthiness of the tools was maintained through consultation with experts, thick description, members check, and triangulation. Thematic interpretation and analyses were interwoven from various datasets for triangulation. The ethical issues related to the research process were evaluated by the research committee of the Dean's Office, Faculty of Education, TU. Participants were informed and consent was taken and requested for voluntary participation. Information obtained from participants was kept confidential with anonymity. Participants were given right to quit anytime of data collection. Respects to the cultural and social norms of participants were paid attention throughout the research process.

\section{Results and Discussion}

\section{Participants' Characteristics}

The details of the participants' characteristics are presented in Table 1 and Table 2. Of total 18 IDIs, 1 was conducted in Dolakha district (Mountain), followed by 8 in Kathmandu and Bhaktapur districts (Hill) and 9 in Chitwan district (Terai). Two FGDs each were conducted in Hill and Terai regions. Due to very low number of teachers in Mountain district, FGD was not possible there. Majority of the participants who participated in the IDIs were males. The number was similar for those participated in the FGDs (16 males). In terms of age, majority of the participants were during the age of $40-49$ years old. See Table 1 and Table 2 for further details.

\section{Knowledge of Set Induction Skill among Health Education Teachers}

The knowledge of set induction skill was found to fairly exist among all the teachers. One of the participants in in-depth interview found it as a starting point of class by motivating students. Similarly, it was perceived as "a pre-motivate stage before the starting of class" by a teacher in Bhaktapur. One of the teachers defined it very critically that as "the process of introducing the subject matter to the students as a preparation to teach the whole period with motivation which includes the things to attract the students and their attention towards the subject matter' (IDI, male Lecturer in Bhaktapur).

Similarly, a teacher in Dolakha too reflected fair knowledge on the opening skills of a class as he said, "teachers and students meet in the classroom, the

Table 1. Approaches used for qualitative data collection.

\begin{tabular}{cl}
\hline \multicolumn{1}{c}{ Data collection types } & \multicolumn{1}{c}{ Number of participants } \\
\hline In-depth qualitative interviews & $\begin{array}{l}\text { 1 IDIs in Dolakha (Mountain district), } 8 \text { in Bhaktapur and } \\
\text { Kathmandu (Hill districts) and 9 in Chitwan (Terai district) }\end{array}$ \\
Focus group discussion & $\begin{array}{l}\text { 2 FGDs with teachers in Chitwan (including 18 teachers), } \\
\text { 2 FGDs in Kathmandu and Bhaktapur (including 15 teachers) }\end{array}$ \\
Classroom class observation & $\begin{array}{l}\text { 1 class observation in Dolakha, 9 in Bhaktapur and Kathmandu } \\
\text { and 9 in Chitwan. }\end{array}$ \\
\hline
\end{tabular}


Table 2. General characteristics of the FGD participants $(n=26)$, IDI participants $(n=18)$ and classroom observation $(\mathrm{n}=19)$ of health edcuation teachers.

\begin{tabular}{|c|c|c|c|}
\hline Characteristics & $\begin{array}{c}\text { FGDs (FGDs; } \\
\text { Total participants, } N=26 \text { ) }\end{array}$ & $\begin{array}{c}\text { IDIs } \\
(N=18)\end{array}$ & $\begin{array}{c}\text { Classroom observation } \\
\qquad(\mathrm{N}=19)\end{array}$ \\
\hline \multicolumn{4}{|c|}{ Work setting } \\
\hline Mountain & - & 1 & 1 \\
\hline Hill & 2 & 8 & 9 \\
\hline Terai & 2 & 9 & 9 \\
\hline \multicolumn{4}{|c|}{ Age by category } \\
\hline $20-29$ & - & - & - \\
\hline $30-39$ & 1 & 1 & 1 \\
\hline $40-49$ & 26 & 11 & 12 \\
\hline$\geq 50$ & 6 & 6 & 6 \\
\hline \multicolumn{4}{|c|}{ Gender } \\
\hline Male & 26 & 15 & 16 \\
\hline Female & 7 & 3 & 3 \\
\hline \multicolumn{4}{|c|}{ Duration of job in the present campus } \\
\hline$<10$ years & 4 & - & - \\
\hline $10-19$ years & 26 & 4 & 4 \\
\hline $20-29$ years & 3 & 14 & 15 \\
\hline
\end{tabular}

interaction begins, and then it is the situation that prepares for reading and training by brain and makes the students ready to enter into the topic" (a male lecturer in Dolakha). Most of the teachers confirmed that it is the beginning of the class which is written on the board if the students are curious, and questions are asked about the previous lesson or today's lesson. All of them linked it to the motivation. However, a teacher opined that it is related to class management systems that might include the seating state of the students, subject matter to be taught and different teaching methods to be used in the classroom. He mixed all the terminologies and showed no precise knowledge regarding it.

It was asked to the teachers about "what are the activities done under set induction". Their views are listed as follows:

"Matter of meditation of previous knowledge and current learning experience" (a female lecturer in Bhaktapur).

"Proceeding teaching new things through summarizing the previous lesson" (a male lecturer in Bhaktapur).

"Motivation to pursue new lessons by creating supportive environment" (a male lecturer in Kathmandu).

"Short interaction of previous lesson" (a male lecturer in Dolakha).

"Information sharing of present subject matter" (a male lecturer in Chitwan). 


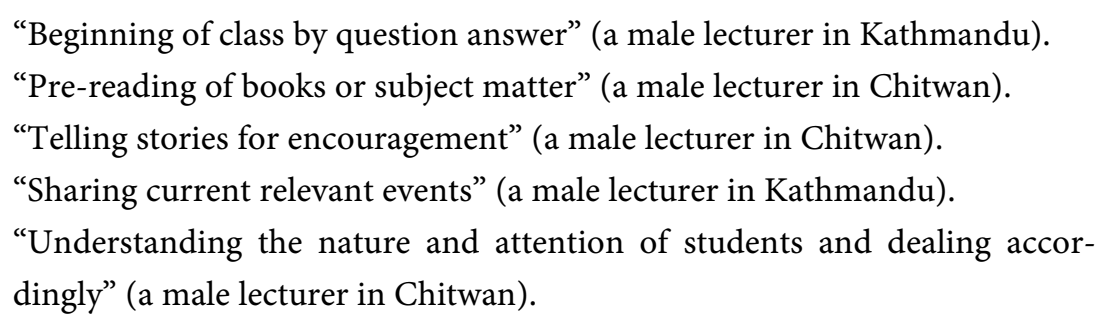

FGDs also revealed good understanding of set induction skill among the teachers. Several teachers during FGDs in Kathmandu and Chitwan emphasized for the necessity of this skill for college level teachers. "Until teachers make students ready for the learning, how can they start class well? Skill of set induction is the process of relating today's lesson with earlier one, indicating today's title and opening the lesson" (a male lecturer in FGD in Chitwan).

All the above listed conceptual understandings are related to the use of previous knowledge to start a class. The fair understanding of the skill of using previous knowledge to start a class was seen among the teachers; however, nobody illustrated well on what is the skill of using appropriate devices to start a class.

\section{Application of Set Induction Skill in Instruction}

FGDs revealed that majority of the teachers were fond of asking content related questions at the start of class to draw student's attention. Female teachers from Bhaktapur and Kathmandu said they used to begin their class by greeting, then linking and revising the previous knowledge and learning experiences. This method was said to be used by many other teachers too. Anything like former knowledge was used in practice and their need and interest are discussed. One of the teachers said, "The previous knowledge is used to start the class by asking the students what they had done yesterday, adding today's theme with the feedback from the students. It differs according to their level' (a male lecturer in Bhaktapur).

A teacher from Kathmandu was found to ask the students about how much they read and what they understand regarding the subject matter. He said, "I tell them the previous day to read, then on the basis of the student's response I come to know their understanding and level of reading habits from where I start my subject matter". It was revealed in FGDs too. Teachers said they practiced this skill by asking questions related to past lesson and writing today's lesson on board.

One of the young teachers in Bhaktapur said he used to bring burning issues related to health education and ask questions to the class to begin with. Contrary to him, a fifty five year old teacher from the same district used to begin the class by writing topic on the board. According to him, even if he used question answer method, only a few students participate in the process. He used to avoid any innovative methods of opening a class and immediately enter to the lesson to be taught.

The main aim of using previous knowledge to start the class was found to identify students' levels. Mostly when the topic was new and not very related to 
the last lesson, teachers used to evaluate the orientation of the students towards that topic through identification of existing knowledge. It mostly followed question answer methods. However, if the previous lesson was related to, they used to revise in short and proceed. Some teachers of Chitwan used this skill to motivate the students. One of the teachers there said, "This is an art, linking today's topic with previous lesson, using former knowledge and calculate the level of students. This helps to motivate them and bind to the lesson".

A teacher from Dolakha finds this skill to encourage and mentally prepare students to the study. This skill is for making atmosphere ready for learning. He said:

"While going into the classroom, I try to prepare them for a delicious time in a delightful and elegant face. I try to attract everyone to study. The national events, news etc. which are related to the topic are shared. It motivates and attracts them to the topic. I everyday get updated to the national/international news and make them worthy to share inside classroom during a short time at the starting of the class".

In observation of the classes, I found this skill not practiced well. Everyone entered the class and opened the session. However, both the skills: use of previous knowledge and use of appropriate devices were not found adequately and properly used. For example, a female teacher in Bhaktapur entered her class with a laptop but she used it as a book and not the device to show presentation slides. She started teaching on "community health" verbally, did not write anything on board, and immediately reached to her topic. She neither used the skill of previous knowledge nor used any appropriate device.

Many other teachers in observations at least linked their lessons with previous lesson. However the linkage was established through asking a question "what did we read yesterday?' It was an attempt to make them recall the past lesson and enter into the today's lesson. When some of the students replied their question, they responded with a hook and then started their lessons immediately. I did not find any teacher providing any related concepts and news, supporting information from the past lesson, and additional information. If they practiced this skill, they usually would ask the question "what did we read yesterday" or in some cases they informed them "we read this thing yesterday, now we are going to study this lesson". Many teachers in Bhaktapur, Chitwan and Kathmandu did the same thing. Generally writing the title on the board was meant to be opening a lesson by almost teachers.

A little different was found in the starting of a teacher in Kathmandu. After entering the class, he wiped out the board, reminded the previous lesson for two minutes and introduced that day's lesson. He excellently started the lesson although he too did not use any appropriate devices like narrations, stories, news, etc.

Most of the teachers were found to use the previous knowledge to start the class, but none of them used appropriate devices to start class. Teachers believed 
to use teaching materials as appropriate device to start class, which is also not in practice. Appropriate devices used for an introduction are narrations, illustration (charts, film strips, slides) questions, similarities and analogies (Allen \& Ryan, 1968). Teachers neither showed proper understanding of using appropriate devices to start class, nor practice it.

There were teachers who had proper knowledge on using previous knowledge to link a class for set induction; however, they could not practice this skill too in reality. Almost of them asked questions related to past lesson, shared events related to present lesson and started teaching. Wiping the board, writing the lesson title, and asking about what they read the day before are methods of set induction, but there are many other things to be done for effective and enthusiastic start, which the teachers could not demonstrate.

Teachers believed that teaching skill is an art and science of teaching health education by a teacher for "students' motivation". Their specific knowledge on various pedagogical skills was found below satisfactory level although they believed that health education is a behavioral subject which requires optimum mix of various pedagogical skills. For them, skill of set induction was beginning of the class. All of them linked it to motivation construct, some could not precisely define it but most of them related it to the use of previous knowledge to start a class. Nobody had knowledge about one of its components "use of appropriate devices" to start a class.

Set induction is about preparation, usually for a formal lesson. When the students are set, they are ready to learn (are you set?). Set induction is thus about getting them ready; it is important in each set both to create clarity about what is expected to happen (both what you will do and what they should do), and to create motivation for this to occur with students being fully engaged in the learning (Perrott, 1988).

In most cases, the initial instructional move of the teacher should be to establish a set (Hedge, 2001). The set focuses students' attention on some familiar person, object, event, condition or idea. The established set functions as a point of reference around which the students and the teacher communicate. In this regard, operant conditioning learning theory contends that an encouraging learning environment should be provided to learners to encourage them to respond appropriate behavior as intended by the curriculum. Furthermore theory of generalization also contents that students can transfer learned knowledge, values, and theories in effective way when they can get an environment which is more likely identical to the context where they obtained such knowledge and skills.

Moreover, cognitive theories of learning also argue that learners can conceptualize abstract contents easily when they are taught by using concrete instructional materials. Different types of assistive technologies or instructional materials, therefore, are very handy to optimize the cognitive skills of students come from diversified backgrounds. The teacher uses this point of reference as a link 
between familiar and new or difficult material. Furthermore, an effective set encourages students' interest and involvement in the main body of the lesson (Richards \& Bohlke, 2011).

\section{Conclusion and Implications}

The health education curriculums of master and bachelor levels at TU are either more content oriented than the pedagogy or the instructional techniques used there are more content focused than the pedagogical implications. This is leading to produce aspiring teachers with less skills of teaching such as the skill of set induction. A competent teacher must be equipped with appropriate skills of starting a class. Curricular contents must be focused in these regarding health education instructions. Moreover to it, the campuses should create appropriate opportunities of practicing these skills during the course teachings to the aspiring teachers. Teacher training program at TU needs to revise the curriculum contents and methods such that the basic skills of teaching are grasped at totality by the aspiring teachers.

In the context, health education teachers in general write the topic on the board and ask what they read yesterday and open up the session. This is what most Nepalese health education teachers do for set induction. Some teachers ask content related questions at the start to draw students' attention, while some use previous knowledge aiming to identify their levels. Some others also evaluate the orientation of students towards the topic if it is new. Teachers in general think that on doing this the students are motivated to learn.

Several psychological experiments have demonstrated the importance of set induction in learning. Research indicates that activities preceding a learning task influence the performance of the task. The research also indicates that the effectiveness of a set depends somewhat on the situation to which it is applied. Hence, teachers must find those kinds of sets most appropriate to their purposes and modify these sets to fit the specific classroom situation.

Before reaching the major content of the lesson, a teacher should introduce the topic to teach and serve as a bridge between new knowledge of a new topic and previously learnt knowledge. Appropriate devices used for an introduction could be narrations, illustration (charts, film strips, slides) questions, similarities and analogies. The educational supervisor or the chief of the teachers training program should supervise and recommend for the change to the teachers. Teachers training programs should include practical sessions for practicing the skill of set induction so that implementations of the learnt skills don't go in vain.

\section{Acknowledgements}

The authors would like to thank the participants who participated in this study.

\section{Conflicts of Interest}

The authors declare that there is no conflict of interest with this research. 


\section{Author Contributions}

KRS conceptualized and conducted the study. KRS prepared draft. BA assisted in field work, edited the manuscript and participated in revision. SS supported in analysis and participated in revision. All the authors did agree to submit this paper for publication.

\section{References}

Aggarwal, J. C. (2014). Essentials of Educational Technology, Innovations in Teaching-Learning (3rd ed.). New Delhi: Vikash Publishing House Pvt. Ltd.

Allen, D., \& Ryan, K. (1968). Micro Teaching. New York: Addison Wesley.

Dyer, J. E., \& Osborne, E. W. (1999). Effects of Student Learning Styles on Short and Long Term Retention of Subject Matter Using Various Teaching Approaches. Journal of Agricultural Education, 40, 11-18. https://doi.org/10.5032/jae.1999.03011

Eisner, E. W. (2017). The Enlightened Eye: Qualitative Inquiry and the Enhancement of Educational Practice. New York: Teachers College Press.

Hargie, O. (2016). Skilled Interpersonal Communication: Research, Theory and Practice. London: Routledge Publishers. https://doi.org/10.4324/9781315741901

Hedge, T. (2001). Teaching and Learning in the Language Classroom. Oxford: Oxford University Press.

Karmacharya, D. M. (2006). Impact of Training on Teaching Behavior and the Factors Influencing It. Kathmandu: Faculty of Education, T.U.

Oman, M. D. (2001). Using Anticipatory Set Demonstrations to Promote Interest in Science: An Investigation into an 8th Grade Integrated Science Classroom. Unpublished Master's Thesis, River Falls, WI: University of Wisconsin.

Oman, M. D. (2002). Student Perceptions of Set Inductions in Technology Education. An Unpublished Master's Thesis, Stout, WI: University of Wisconsin.

Perrott, E. (1988). Effective Teaching. London and New York: Longman.

Popkewitz, T. S. (2012). Paradigm and Ideology in Educational Research: The Social Functions of the Intellectual. London: Routledge.

https://doi.org/10.4324/9780203127957

Richards, J. C., \& Bohlke, D. (2011). Creating Effective Language Lessons. Cambridge: Cambridge University Press.

Schuck, R. F. (1970). Set Induction as an Instructional Strategy for Science Educators. The Science Teacher Journal, 37, 63-65.

Schunk, D. H. (2012). Learning Theories an Educational Perspective. Boston, MA: Pearson Education Inc.

Wiggins, G., \& McTighe, J. (2005). Understanding by Design (2nd ed.). Alexandria, VA: Association for Supervision and Curriculum Development. 